\title{
Meeting need vs. sharing the market: a systematic review of methods to measure the use of private sector family planning and childbirth services in sub-Saharan Africa
}

\author{
Mardieh L. Dennis ${ }^{1 *}$ (D) Lenka Benova', Onikepe O. Owolabi² and Oona M. R. Campbell ${ }^{1}$
}

\begin{abstract}
Background: Ensuring universal access to maternal and reproductive health services is critical to the success of global efforts to reduce poverty and inequality. Engaging private providers has been proposed as a strategy for increasing access to healthcare in low- and middle-income countries; however, little consensus exists on how to estimate the extent of private sector use. Using research from sub-Saharan Africa, this study systematically compares and critiques quantitative measures of private sector family planning and childbirth service use and synthesizes evidence on the role of the private sector in the region.

Methods: We conducted a systematic review of the Medline, Global Health, and Popline databases. All studies that estimated use of private sector of family planning or childbirth services in one or more sub-Saharan African countries were included in this review. For each study, we extracted data on the key study outcomes and information on the methods used to estimate private sector use.

Results: Fifty-three papers met our inclusion criteria; 31 provided outcomes on family planning, and 26 provided childbirth service outcomes. We found substantial methodological variation between studies; for instance, while some reported on service use from any private sector source, others distinguished private sector providers either by their profit orientation or position within or outside the formal medical sector. Additionally, studies measured the use of private sector services differently, with some estimating the proportion of need met by the private sector and others examining the sector's share among the market of service users. Overall, the estimates suggest that the private sector makes up a considerable portion (> 20\%) of the market for family planning and childbirth care, but its role in meeting women's need for these services is fairly low $(<10 \%)$.

Conclusions: Many studies have examined the extent of private sector family planning and childbirth service provision; however, inconsistent methodologies make it difficult to compare results across studies and contexts. Policymakers should consider the implications of both private market share and coverage estimates, and be cautious in interpreting data on the scale of private sector health service provision without a clear understanding of the methodology.
\end{abstract}

Keywords: Private sector, Family planning, Maternal health, Systematic review, Africa

\footnotetext{
* Correspondence: mardieh.dennis@lshtm.ac.uk

${ }^{1}$ Faculty of Epidemiology \& Population Health, London School of Hygiene \&

Tropical Medicine, Keppel Street, London WC1E 7HT, UK

Full list of author information is available at the end of the article
}

(c) The Author(s). 2018 Open Access This article is distributed under the terms of the Creative Commons Attribution 4.0 International License (http://creativecommons.org/licenses/by/4.0/), which permits unrestricted use, distribution, and reproduction in any medium, provided you give appropriate credit to the original author(s) and the source, provide a link to the Creative Commons license, and indicate if changes were made. The Creative Commons Public Domain Dedication waiver (http://creativecommons.org/publicdomain/zero/1.0/) applies to the data made available in this article, unless otherwise stated. 


\section{Background}

As the international development community shifts its focus from the Millennium Development Goals to the Sustainable Development Goals, universal access to maternal and reproductive health services remains critical to the global strategy for poverty and inequality reduction [1,2]. Many low- and middle-income country governments have rolled out strategies to increase supply of and demand for public sector family planning and childbirth services [3-8]. However, some argue that reliance on the public sector alone to expand access to health services is impractical and that harnessing the contribution of private, non-government actors is the key to achieving universal healthcare coverage in low- and middle-income settings [9-11]. Proponents of publicly-financed health services, on the other hand, argue that encouraging growth of the private health sector is likely to exacerbate inequalities in access to care by making services financially unattainable for the poor $[9,12,13]$.

Understanding non-government actors' current contribution to health service provision is critical for determining if, how, and in which contexts to engage the private sector. While many studies have attempted to quantify the contribution of the private sector in lowand middle-income country (LMIC) contexts, there has been relatively little discussion of the philosophical and methodological considerations of doing so. One major challenge is defining what constitutes the "public" and "private" sectors. While sector is often defined in terms of the ownership or management of a health facility and dichotomized as public versus private, past research on health systems in LMICs has acknowledged that formalized partnerships between government-owned and non-government entities, government financing of private providers, and the practice of providers offering services in both government and privately-operated facilities have resulted in challenges in distinguishing the two sectors $[14,15]$. Additionally, researchers of organizational theory argue that this public-private dichotomy does not adequately capture the range of factors that determine the degree to which a health facility or organization is publicly-oriented, and that health organizations should, instead, be conceptualized along a multi-dimensional continuum including ownership, financing, and mission. [16, 17]. These more nuanced definitions of sector, however, require details about health providers that are often not available or infeasible to collect in population-level assessments of the use of providers in different sectors.

Using an ownership-based definition of sector, private providers are believed to provide a substantial portion of maternal and reproductive health services in low- and middle-income countries; however, estimates of their role seem to vary considerably between studies and contexts [18, 19]. For instance, one recent study using Demographic and Health Survey (DHS) data reported that $38 \%$ of modern family planning users and in sub-Saharan Africa sought care in the private sector, while another recent study, also using DHS data, estimated this figure at $28 \%[20,21]$. Though some of the variation between the two estimates is due to different countries being included in the analyses, inconsistencies in how these percentages were calculated also had an effect.

Differences in measurement approaches increase the likelihood of researchers over- or underestimating the role of the private sector in provision of family planning and childbirth services. Using research from sub-Saharan Africa, this review has two main objectives: (1) to systematically compare and critique quantitative measures of private sector family planning and childbirth service use and (2) to descriptively synthesize evidence of the contribution of the private sector family planning and childbirth service use in the region. Further, by examining both an outpatient service largely requiring low- to mid-level clinical skills (family planning) and an inpatient service requiring mid- to high-level clinical skills (childbirth care), this study will highlight how the identified methodological approaches affect private sector use estimates for services delivered through different channels of the health system.

\section{Methods}

\section{Scope of review}

For the purposes of this review, we considered the private sector to encompass all providers owned by non-government actors. Given the descriptive nature of our outcomes of interest, peer-reviewed and grey literature papers of any study design were eligible for inclusion. We did not apply any restrictions on language or date of publication. For each study, we summarized the methods used to measure private sector service provision and the estimates reported. We discussed the strengths and weaknesses of the methods used in each study and how they might have biased the findings. This review is not registered and does not have a published protocol. Additional file 1 contains a Preferred Reporting Items for Systematic Reviews and Meta-Analyses (PRISMA) checklist for this review.

\section{Search strategy}

We identified studies by searching the Medline, Global Health, and Popline databases, using a combination of keywords and $\mathrm{MeSH}$ terms covering the following broad themes: (1) sub-Saharan Africa, (2) contraception or childbirth services, and (3) private sector. Additional file 2 contains the full list of keywords and MeSH terms used. We conducted our search on October 26, 2016. A total of 3,620 records were identified from the three databases and imported into Covidence, an online systematic review management platform. After removing duplicates, the titles and abstracts of 2,041 publications were 
screened for inclusion in the review. Publications clearly outside of the scope of the review, covering topics unrelated to use of family planning or childbirth services in sub-Saharan Africa, were excluded at this stage, while the 126 studies that appeared definitely or potentially relevant were selected for full text screening. MLD and OOO screened the studies at each stage, and any discrepancies were discussed and resolved. Studies that did not present private sector use estimates for family planning or childbirth care, or that combined figures for multiple services, were excluded. Studies that did not present outcomes for at least one sub-Saharan African country, or presented estimates from sub-Saharan Africa pooled with those from other regions, were also excluded. We selected 37 studies for inclusion in the review; 16 additional papers were identified through systematically scanning the references of all included studies (Fig. 1). MLD extracted information on the included studies' methods and results for this analysis.

\section{Results}

\section{Overview of included studies}

Fifty-three papers met our inclusion criteria; 31 included outcomes on family planning, while 26 provided outcomes on childbirth services (Additional file 3). Studies on private sector provision of family planning and childbirth services in sub-Saharan Africa have proliferated in recent years, with the number of included papers published during the 6-year period from 2011 to 2016 exceeding the number published over the preceding 25 years combined (Fig. 2).

The included papers provided estimates of private sector family planning or childbirth service use for 40 countries in sub-Saharan Africa over a 30-year period from 1984 to 2014. Certain countries, such as Ghana, Kenya, and Zimbabwe, were studied extensively over time while others, such as the Gambia and Somalia, were not studied at all (Additional file 4).

More than half of the included studies focused on a single country $(n=31)$; the remaining studies included

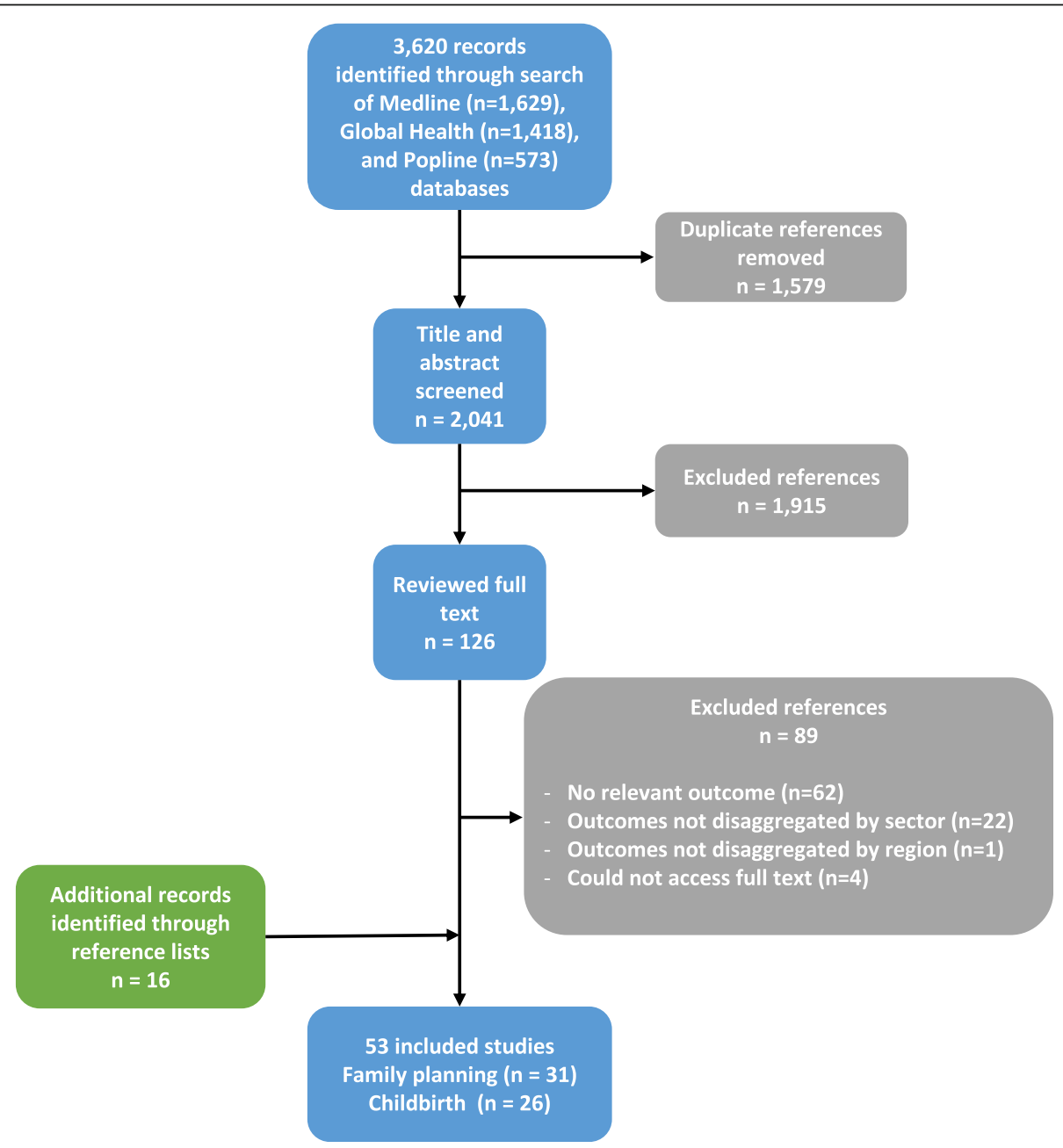

Fig. 1 PRISMA flow diagram 


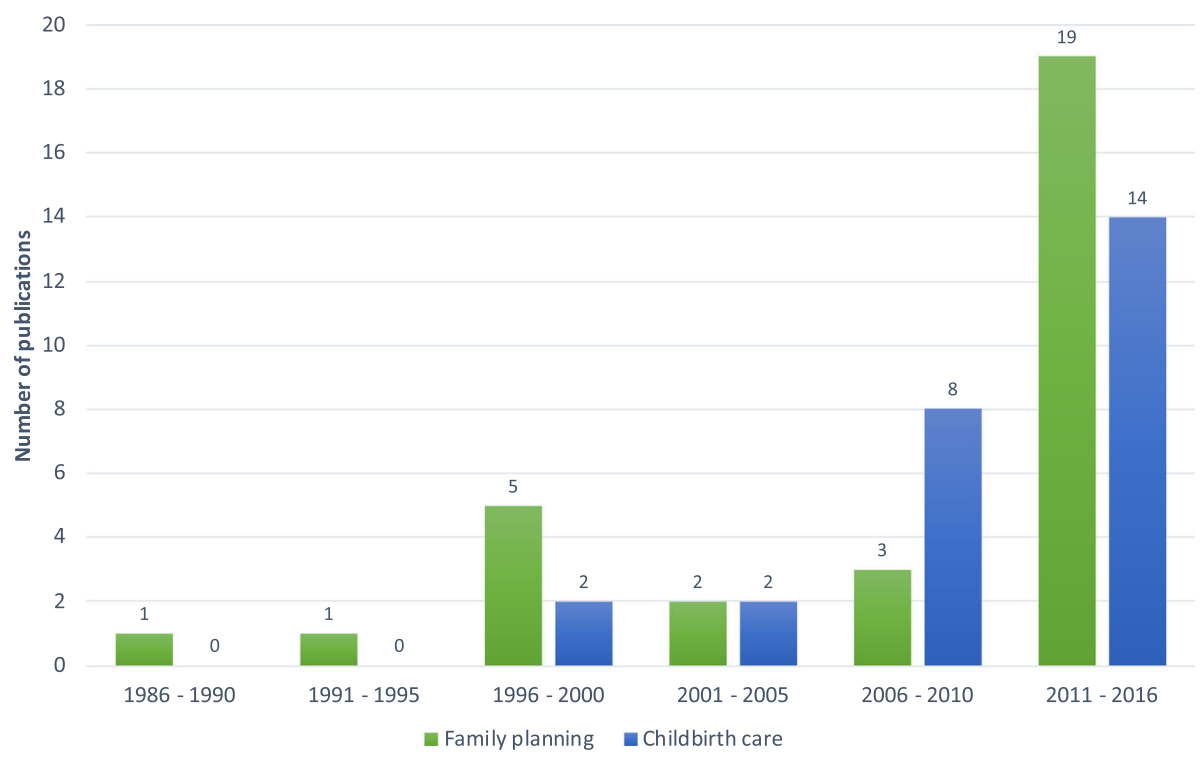

Fig. 2 Number of included studies by publication date

multi-country comparative analyses of two to 36 countries. The majority of studies looked at cross-sectional data at one point in time $(n=40)$, while 13 studies examined trends over time using repeated cross-sectional data [21-33].

\section{Measuring use of private sector family planning \& childbirth services \\ Data sources}

Forty-seven of the 53 studies used household survey data to estimate use of private sector family planning and/or childbirth services; the majority of these studies used the Demographic and Health Surveys $(n=27)$, while others used data from demographic surveillance sites [34, 35], national maternal health surveys [36], or other smaller, sub-national surveys [23, 24, 37-50]. Three studies conducted surveys that sampled women at a health facility [51], market [52], or through respondent-driven sampling [53]. The remaining three studies used routine health service statistics to estimate the proportion of facility births that occurred within the private sector [54-56].

\section{Source of care: Defining the private sector}

The studies included in this review contained over 40 unique terms to describe private sector sources of family planning and childbirth services (Additional file 5). Throughout the literature, the "private sector" referred to a range of for-profit, not-for-profit, faith-based, medical, and informal providers that were managed by non-government actors. While some studies reported on service use from any private sector source, others distinguished private sector providers by two key characteristics: (a) their commercialization or profit orientation and/or (b) their position within or outside of the medical sector (Fig. 3). Among the included studies, the private for-profit sector included both medical and non-medical providers, while the private non-profit sector seemed to refer exclusively to medical providers. Additional file 6 displays the frequency with which each unique private sector term appeared in the included studies, categorized by profit orientation.

\section{Populations under study: Coverage vs. market share}

The studies included in this review examined private sector use within two general population groups: (1) women in need or "at risk" of needing family planning or childbirth services and (2) users of those services. We used the term private sector coverage to indicate the proportion of women in need who were using family planning or childbirth services from a private sector source, or the proportion of health service need met by the private sector. Private sector market share, on the other hand, refers to the proportion of family planning or childbirth service users who received care from a private sector source. Of the 31 studies that examined use of private sector family planning services, five reported coverage estimates [20, 21, 57-59], 30 reported market share estimates, and four reported both market share and coverage estimates [20, 21, 57, 59] (Additional file 6). For childbirth services, 22 of 26 papers presented private sector coverage estimates, seven reported on private sector market share [35, 52, 54-57, 60], and three reported both market share and coverage estimates $[35,57,61]$ (Additional file 6). Although we grouped these outcomes into two broad categories, there was substantial variation within each category in how these populations were 


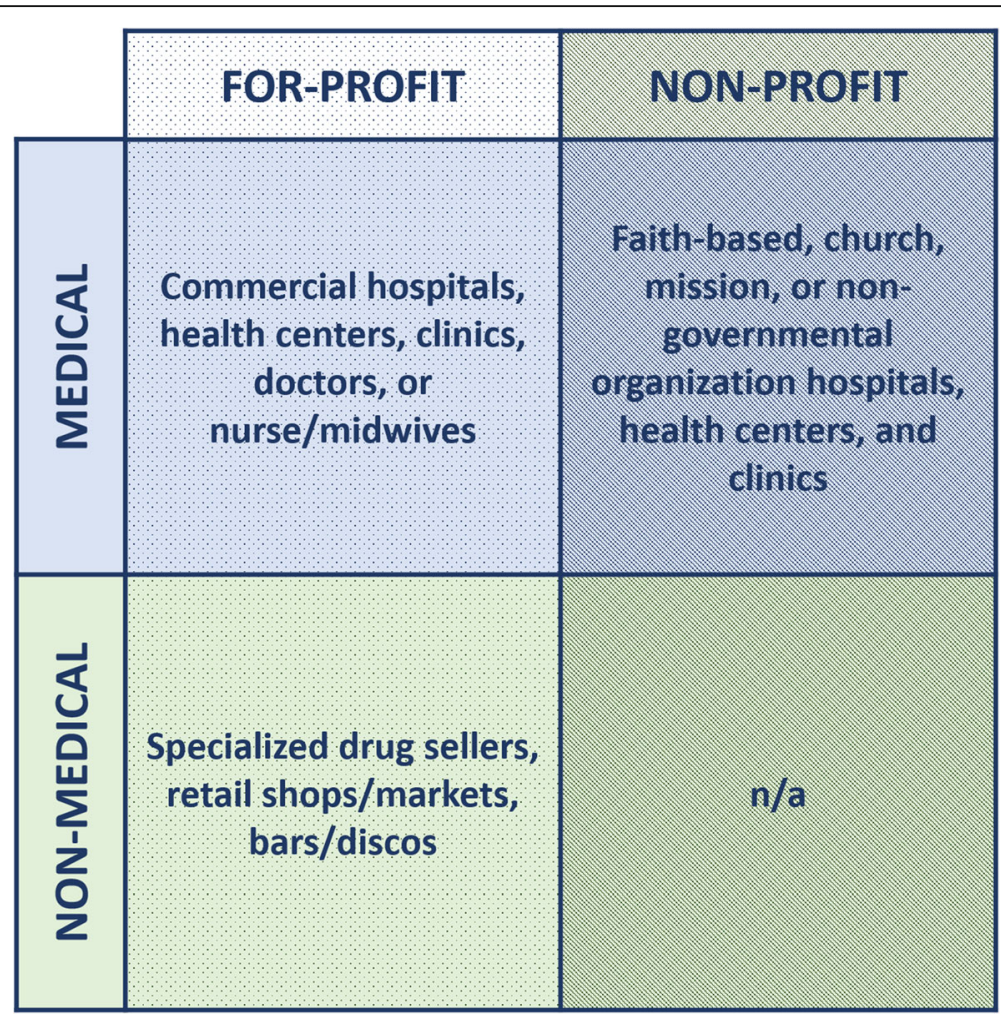

Fig. 3 Classification of private sector providers

defined. For instance, three studies considered the population in need of family planning to be all women married or in union (regardless of fertility preferences or desires) $[21,58,59]$, while two studies reported use among all women with $\mathrm{d}$ need for family planning (regardless of marital status) [20,57], following the most recent consensus definition of need for contraception [62]. We summarized the different populations used to examine private sector coverage and market share in Fig. 4.

\section{Unit of analysis}

There were differences between studies in the unit of analysis for examining source of family planning and childbirth services. Of the 31 studies that reported on use of private sector family planning services, 13 described source of care during women's most recent supply of contraceptives [20, 22, 24-26, 29, 31, 41, 50, 53, 58, 59, 63] and one described where women obtained care when they first started using their current method [40]. The majority of studies $(n=17)$, however, did not state their unit of analysis $[19,21,27,28,38,39,42,44,45,51,57,64-68]$.

When describing use of childbirth services, the included studies generally adopted either a birth-based $(n=6)[23,54-56,69,70]$ or a woman-based approach $(n=13)[24,30,36,37,43,46-50,57,60,68]$. The unit of analysis for birth-based approaches was all births that occurred over the study recall or review period. The woman-based approach, on the other hand, included only one birth per woman, and all of the included studies adopting this approach used a woman's most recent birth as the unit of analysis. One study used a hybrid approach, taking information about all of a woman's births and categorized her according to where she sought care across births [32]. Six of the 26 studies that reported on use of private sector childbirth services did not state their unit of analysis [34, 35, 52, 71-73].

\section{Treatment of missing information}

Although missing information on source of care and family planning and childbirth service use and need has the potential to bias estimates, relatively few studies described how they treated such missing information.

Of the studies that examined private sector market share for family planning and childbirth services, only 9 out of $30[20,24,25,27,40,42,57,63,67]$ and two out of seven $[57,60]$, respectively, indicated how missing data on source of care was treated. Among the studies that did provide this information, the convention was to either include women with missing information as part of the market, but report their source of care as missing or unknown, or to exclude them from the market entirely.

Of the five studies that reported on private sector coverage of family planning services, only two described 


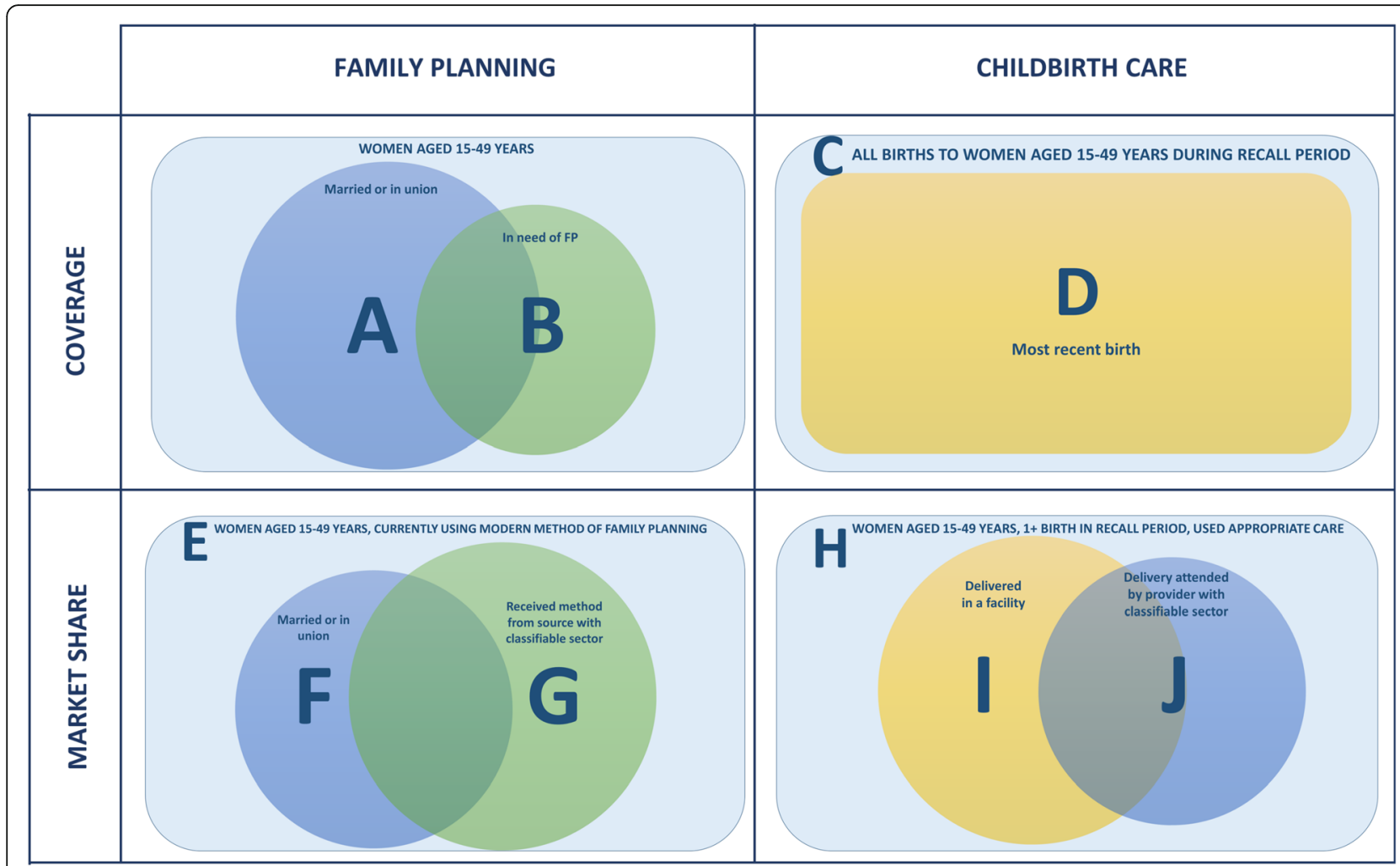

Fig. 4 Denominators for measuring private sector coverage and market share in included studies

how they treated women with missing data on family planning need $[20,57]$ and three described how they treated women with missing data on source of care $[20,57,58]$. In those studies, women with incomplete information on family planning need were considered to be not in need of contraception, while those with missing information on source of care were considered to not have received care in the private sector. For childbirth services, all reported deliveries were considered in need of care. Campbell et al. [8] is the only study that discussed missing information on delivery care need, and the authors found no missing data for that variable [57]. Six of the 22 studies that examined private sector coverage of childbirth services reported that women with missing information on source of care were considered to have not received care in the private sector $[24,35,36,43,57,60]$.

\section{Use of private sector family planning and childbirth services in sub-Saharan Africa}

Given the differences in how use of private sector family planning and childbirth services were defined and calculated, as well as the many settings and periods in which these studies took place, we observed considerable heterogeneity in the estimates of our key outcomes of interest (Additional file 6). To assess trends in outcomes for the region as a whole, and to highlight the influence of methodological differences, we summarized the minimum, maximum, and median national and sub-national estimates of private sector coverage and market share for family planning and childbirth services in sub-Saharan Africa by period under study in Figs. 5, 6 and 7. Aggregated regional estimates are not represented in the figures. To facilitate comparisons between studies, we only included those that provided coverage or market share estimates representing at least one of the following private sector provider classifications: (1) all private sector, (2) private for profit, (3) private non-profit, (4) private medical, or (5) private non-medical. For family planning studies, we only included estimates for private sector market share and coverage for all modern methods; estimates for individual methods or that included traditional methods were excluded.

\section{Family planning coverage}

Ugaz et al. [21] estimated that private sector coverage among women married or in union was relatively low in the sub-Saharan Africa region, ranging between 3 and 6\% from 1992 to 2012. Looking exclusively at the population of women in need of contraception, regardless of marital status, Campbell et al. [20, 57] estimated higher private sector coverage, with $14 \%$ private sector coverage of modern contraceptive need. Similarly, comparing Fig. 5a and b, 


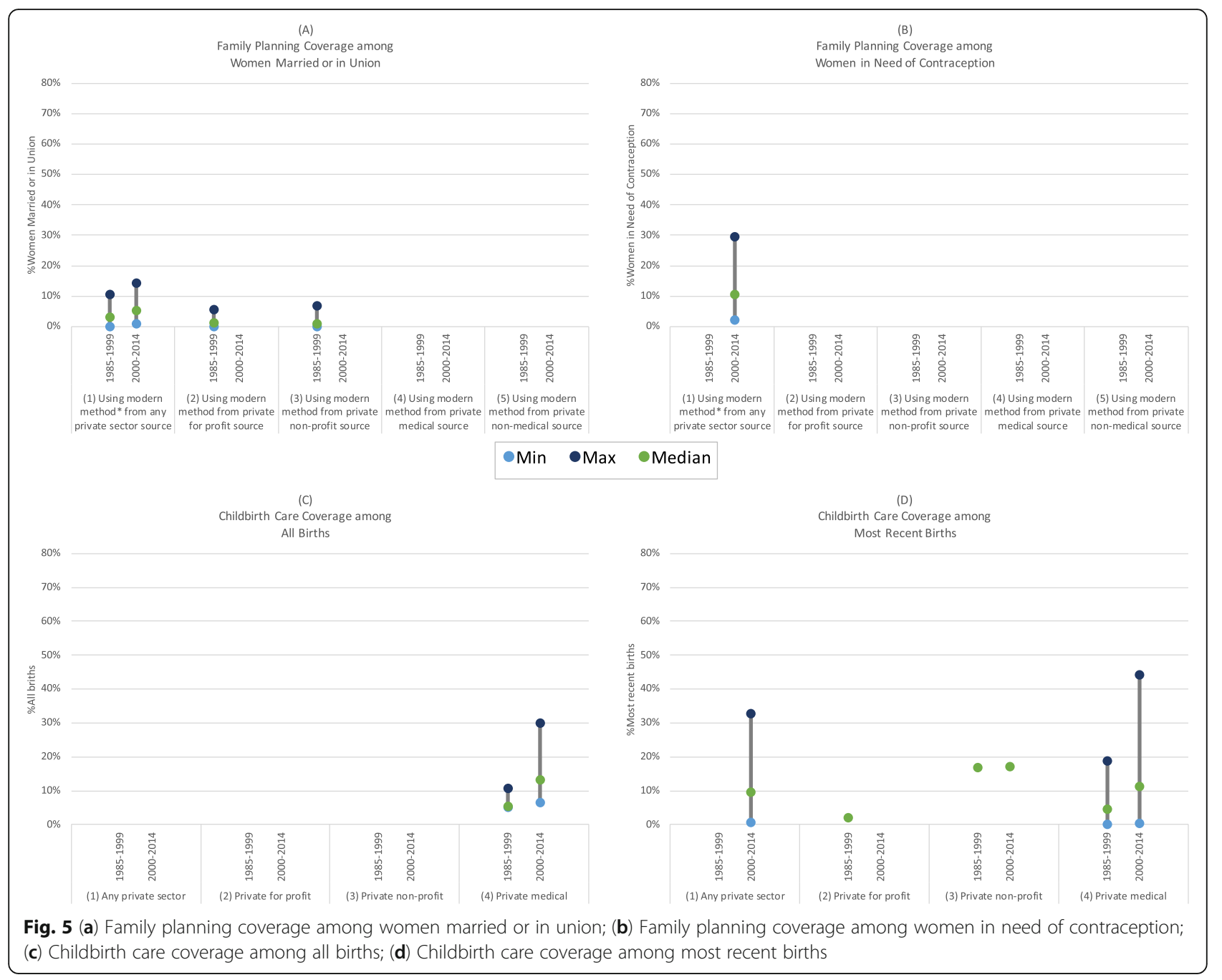

we observed that estimates of private sector family planning coverage tended to be higher among women in need compared to all women married or in union [20, 21, 58, 59]. As expected, the proportions of women using modern methods from private non-profit or for-profit providers was smaller than the proportion of women using modern methods from any private sector source.

\section{Childbirth service coverage}

Benova et al. (2015) estimated that $10 \%$ of women in sub-Saharan Africa delivered in the private sector for their most recent birth, either at a private facility or in a non-facility location with a private medical provider, while Wodon et al. (2012) generated a lower estimate, at $6.8 \%$ of women $[61,68]$. Yoong et al. [70] estimated that an average of $7.7 \%$ of all births in the region received childbirth care from a private medical provider, specifically in a private medical facility. In Fig. $5 c$ and d, estimates of private sector coverage appeared to be quite similar and increasing between the 1985-1999 and
2000-2014 periods, with median values increasing from 5 to 14 and 4 to $11 \%$ among all births and most recent births, respectively [23, 24, 30, 36, 46, 48, 50, 68, 69]. Private non-profit provider coverage of most recent births was estimated around $17 \%$ in both periods, and private for profit provider coverage appeared negligible; however, the studies reporting on this outcome were conducted exclusively in rural areas in Kenya and Tanzania with access to a mission hospital $[46,49]$.

\section{Family planning market share}

We observed much greater heterogeneity in estimates of private sector market share estimates for sub-Saharan Africa compared to those of private sector coverage. Campbell et al. $[8,20,57]$ estimated that $35 \%$ of all modern family planning users and $38 \%$ of modern family planning users who received their method from a source with a classifiable sector obtained care from a private sector provider. Figure $6 \mathrm{~g}$ shows that the family planning market share among women who 


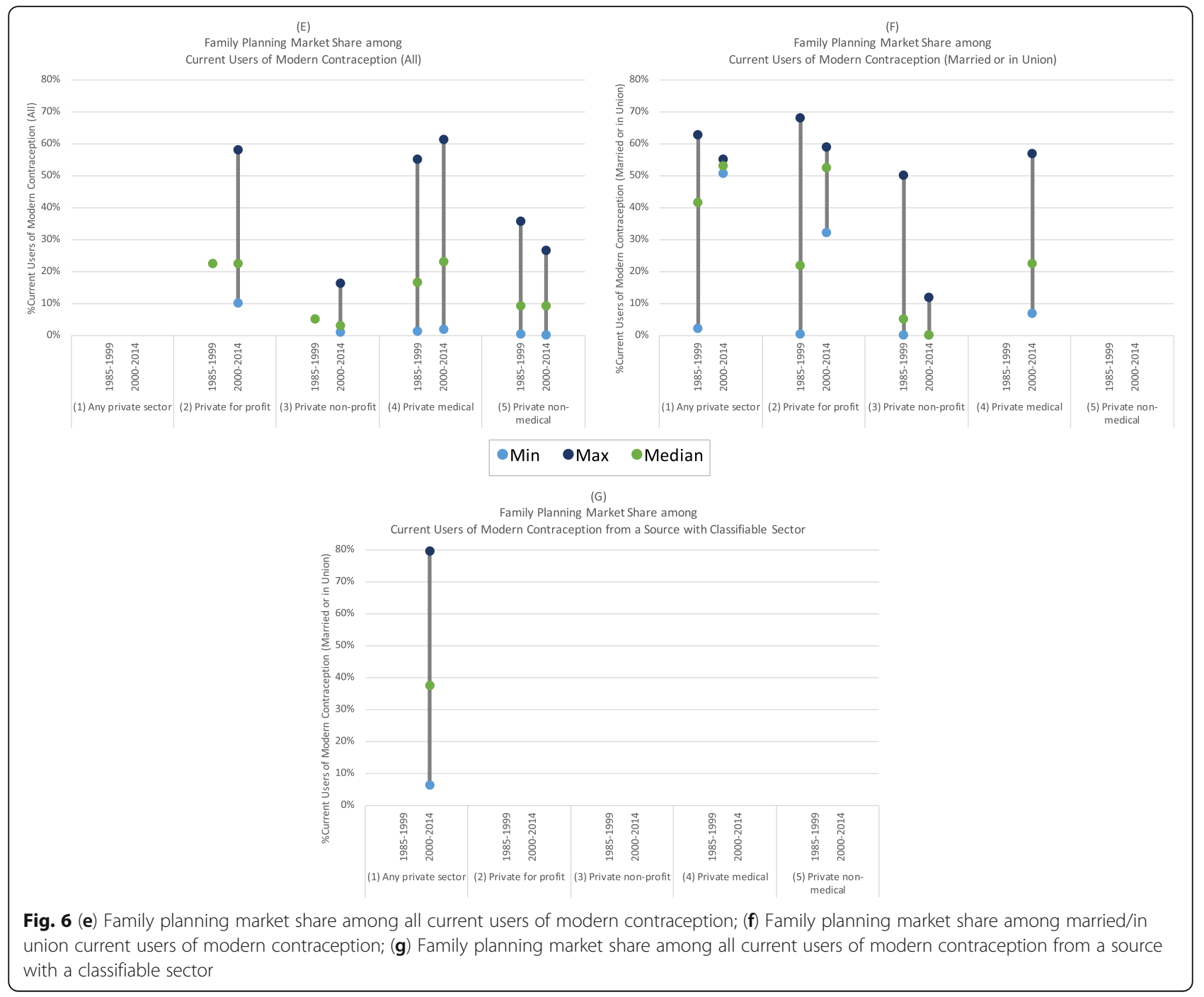

obtained care from a source with a classifiable sector ranged from 6\% in Rwanda (2010) to 80\% in Gabon (2012) [20].

Both Ugaz et al. [21] and Wodon et al. [68] estimated that approximately $28 \%$ of all modern family planning users in sub-Saharan Africa received their method from a private medical provider. This ranged from countries with less than 2\% private medical market share (Burundi, 1987; Sao Tome and Principe, 2008/9) to countries with greater than $60 \%$ private medical market share (Democratic Republic of the Congo, 2007; Nigeria, 2008) (Fig. 6e) [50, 68, 74].

Among all users of modern contraception and those married or in union, private for-profit providers appeared to have a greater market share compared to private non-profit providers (Figs. 6e \& 6f) [22, 29, 33, 41, 59, 66-68]. There also seemed to be greater use of private medical providers compared to non-medical providers among current users of modern contraception; however, this may be because Wodon et al. (2012) classified pharmacies as medical providers while others distinguished facilities from pharmacies or specialized drug sellers (Fig. 6e) [50, 67, 68].

\section{Childbirth service market share}

Only two studies comprehensively examined childbirth service market share across a large number of countries [57, 61 . Benova and colleagues estimated that $20 \%$ of women who gave birth under appropriate care conditions (in a facility or with a skilled-birth attendant) in sub-Saharan Africa received care in the private sector (Fig. 7h) [61]. Looking at source of care among women who received appropriate care from a provider with a classifiable sector increased this estimate slightly to $22 \%$ (Fig. 7j) [57, 61]. Three smaller studies from Kenya, South Africa, and Uganda examined private sector market share among facility births, and estimates ranged from 15\% (South Africa, 1990) to 36\% (Uganda, 2007) [35, 54, 55]. One study from Kenya found that private for- profit providers had a greater market share among facility births (10\%) compared to private non-profit 


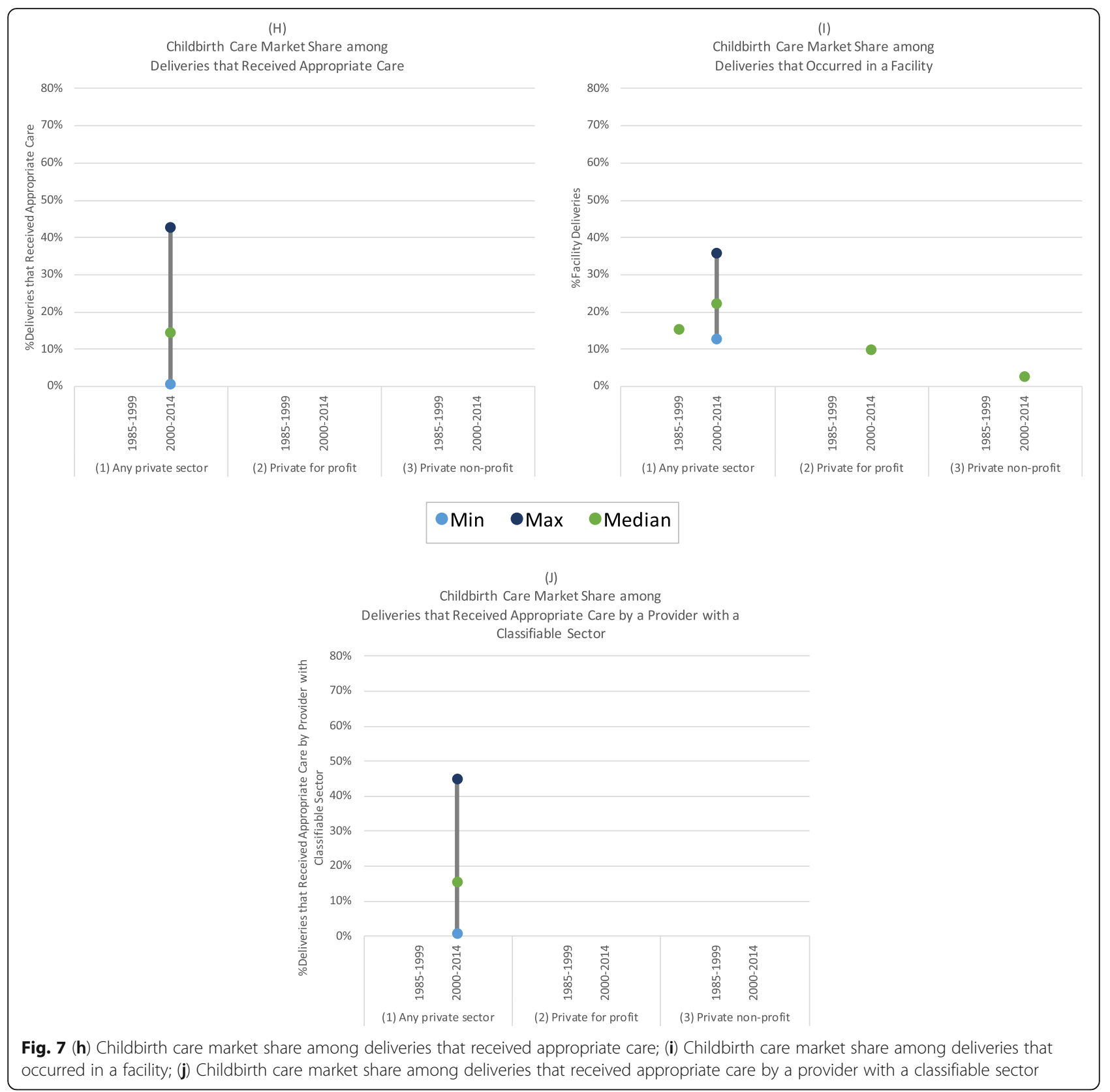

providers (3\%) [54]. In contrast to private sector family planning market share, none of the estimates of private sector market share for childbirth services exceeded $45 \%$.

\section{Discussion}

We identified 53 papers that estimated use of private sector family planning and childbirth services in sub-Saharan Africa. Consistent with beliefs about the private sector's role in the delivery of healthcare in low- and middle-income countries more generally, our findings suggest that in many African nations, the private sector provides a substantial proportion of both family planning and childbirth services among service users $[18,19]$. However, among women in need of these services, private sector coverage is comparatively low. Further, these results suggest that the private sector provided more family planning services than childbirth care in the region. This is due to the less specialized nature of certain family planning methods such as condoms, which allow for provision of services by lower-skilled drug sellers and commercial shops. Although the included studies provided estimates for a majority of countries in the region, it is important to acknowledge that some countries were not studied or have estimates that are outdated or not representative at the national level.

More revealing, however, are our findings on the lack of consistency with which researchers defined the private 
sector and measured its use. While there is clear heterogeneity between countries in the actual role of the private sector, methodological differences also have the potential to greatly affect estimates of private sector participation. It is therefore important to understand the strengths and weaknesses of each analytical approach when interpreting findings.

When it comes to defining the private sector, a more inclusive definition naturally yields a higher estimate. The extent to which including or excluding certain segments of the private sector biases an outcome depends both on context and the service being examined. For instance, while private non-medical providers can conceivably provide a number of modern family planning methods such as condoms or pills, appropriate delivery care should, according to World Health Organization recommendations, occur with a skilled health provider, namely a midwife or doctor [75]. Thus, only examining private medical provision of services is likely to present an incomplete picture of the role of the private sector in delivering family planning services, but a more accurate picture for appropriate childbirth care. As has been noted elsewhere, non-profit and faith-based services are often provided in collaboration with governments and therefore may be difficult to distinguish from public sector care, particularly when relying on women providing self-recall survey data [14, 15, 76-78]. Estimates of all private sector and private non-profit sector service provision are therefore likely to underestimate their true contributions.

Selecting which population to study also requires careful consideration. Examining use of the private sector within a broader population tends to yield lower estimates compared to use among a more narrowly defined population group. As a result, coverage estimates are always equal to or less than market share. In contexts where use of a service is universal or very high within a population, coverage will be equal or similar to, but lower than, market share. In contexts where use of a service is moderate or low, coverage will be much lower than market share.

Because private sector coverage is bounded by total use of a service, comparing private sector coverage estimates between countries with very different levels of total use is challenging. For example, a country (A) with very high use of family planning services, but very low use of the private sector among users, might have the same absolute private sector coverage as a country (B) with low use of family planning services, but very high use of the private sector among users. In such a case, examining coverage alone would lead to the conclusion that the private sector plays a similar role in service provision in each country; however, looking at market share would reveal very different dynamics at play. Similarly, looking at market share alone might lead one to conclude that the private sector serves a greater proportion of the population in country B than in country A, whereas coverage estimates would indicate that the share of total need satisfied by the private sector is similar in both countries.

Population selection also has important implications on estimates within the categories of coverage and market share. Researchers frequently measure private sector family planning coverage as the use of modern contraception from a private sector source among women married or in union, and less frequently among all women in need of contraception. To estimate the latter requires including women who are sexually active but not in union, and excluding women not in need of contraception because they are pregnant or because they wish to have more children in the near future. For secondary analysis of survey data with limited information on fertility preferences and need for contraception, examining use of private sector services among married women might be a reasonable approach. However, this will certainly underestimate private sector coverage given that some proportion of the married population desire to become pregnant and are therefore not in need of contraception. The papers included in this review have also looked at market share among all current users of modern contraception and current users who are married or in union only. Given that service use by married women might not represent the population of women in need, it is preferable to look at source of care for all current users, unless the purpose of the analysis is to compare the experiences of married women to the general population or to unmarried women.

Among papers that looked at private sector family planning market share among all users of modern contraception, regardless of marital status, some limited analysis to women who received care in the private or public sectors. Excluding women who received care from a source whose sector could not be classified from the population under study leads to slightly higher estimates of private sector market share; the extent of overestimation depends on the size of the "unknown sector".

Another consideration when estimating private sector family planning market share is whether to examine source of care when a woman most recently received her current method or when she first received the method. While most papers in this review examined most recent source, it might also be important to understand where women went to start and whether they switch the source of their current family planning method.

For private sector childbirth care coverage estimates, researchers generally used a birth-based approach, looking at use of private sector childbirth services among all births that occurred during a given period, or a woman-based approach, examining source of care for a woman's most 
recent birth. Analyzing all births allows for a larger sample size and better represents births that occurred within a given period among women with both short and long birth intervals. Analyzing private sector childbirth care use among most recent births only, on the other hand, will over-represent births to women with longer birth intervals. As women with short birth intervals are often less likely to deliver in a facility or have a skilled attendant at birth $[79,80]$, private sector coverage among all births is likely to be lower than among coverage for most recent births only. Nevertheless, estimates using all births and those using the most recent birth appear similar; suggesting neither approach greatly affects the conclusions about source of care.

Some studies that examined private sector market share for childbirth services specifically looked at the use of the private sector among women who received appropriate delivery care, defined as either by a skilled birth attendant or in a health facility. Estimating the market share among facility births only excludes provision of care at home or in another non-facility setting by a private medical provider, and therefore may underestimate private sector market share for childbirth services. However, in contexts where home deliveries with a skilled birth attendant are rare, looking exclusively at facility births is unlikely to greatly affect private sector childbirth service market share estimates. As with family planning market share, focusing solely on use of the private sector among users of childbirth services from providers with a classifiable sector generated a slightly greater estimated private sector childbirth care market share compared to analysis of use among all users of appropriate childbirth services.

Although missing data on need for services and source of care has the potential to impact estimates of private sector provision of family planning and childbirth services, relatively few papers in this review discussed the extent or treatment of missing data. To ensure that findings can be clearly interpreted, it is important for researchers to acknowledge and describe the effects of missing information on their outcomes.

On a more practical level, data collection methods also influence the type of private sector use outcome that can be estimated. As private sector coverage requires information on the number of women in need who do not seek care, it can only be measured through population surveys. Facility records can be used to estimate private sector market share among facility births if private sector facilities report births, and this would approximate private sector market share for childbirth services in settings where home births with skilled attendants are uncommon. If health facility records are accurate and women tend to seek care within their catchment area, this may be more cost effective than population surveys for estimating private sector childbirth service market share for a given geographic region. Considering the wide range of private sector medical and non-medical outlets through which modern methods of family planning can be accessed, it would be much more difficult to ascertain private sector family planning market share through facility records.

\section{Conclusion}

Our review suggests that the private sector plays a substantial role in the delivery of family planning and childbirth services in sub-Saharan Africa. Interest in the role of private sector provision of health services in low- and middle-income countries continues to grow; however, there appears to be lack of consensus on how to appropriately measure and report the use of private sector services. Though a plethora of studies have examined the role of the private sector in providing family planning and childbirth services in sub-Saharan Africa, inconsistencies in how researchers define the private sector and measure its use make it difficult to compare results across studies and contexts. Slight changes in methodology can have substantial impact on private sector service provision outcomes. To ensure correct interpretation of findings, it is therefore imperative that researchers better describe their methods and acknowledge the potential biases in their analytical approaches. Additionally, national- and regional-level policymakers should consider the implications of both private market share and coverage estimates and take care in interpreting data on the scale of private sector health service provision without a clear understanding of the methodologies used.

\section{Additional files}

Additional file 1: PRISMA checklist. (DOC $62 \mathrm{~kb}$ )
Additional file 2: Key Words \& MeSH Terms for Literature Review.
(DOCX $104 \mathrm{~kb}$ )

Additional file 3: Descriptive summary of studies included in review. (DOCX $46 \mathrm{~kb}$ )

Additional file 4: Studies on private sector family planning or childbirth care use by country \& period. (PDF $257 \mathrm{~kb}$ )

Additional file 5: Frequency of terms used to describe private sector sources in included studies. (PNG $336 \mathrm{~kb}$ )

Additional file 6: Included study methods and results summary. (DOCX $121 \mathrm{~kb})$

\section{Abbreviations \\ DHS: Demographic and Health Survey; LMIC: Low- and middle-income coun- try; PRISMA: Preferred Reporting Items for Systematic Reviews and Meta- Analyses \\ Funding \\ This work was supported by $\mathrm{a}+3$ Economic and Social Research Council PhD studentship grant award.}

Availability of data and materials

The data supporting the conclusions in this article are available in the additional files. 


\section{Authors' contributions}

MLD conceptualized the study with input from LB and OMRC. MLD and $\mathrm{OOO}$ independently screened and selected included papers. MLD conducted data extraction, analysis, and prepared the first draft of the manuscript. All authors contributed to the interpretation of the results and the preparation of the final manuscript. All authors read and approved the final version.

\section{Ethics approval and consent to participate}

Not applicable

\section{Consent for publication}

Not applicable

\section{Competing interests}

The authors declare that they have no competing interests.

\section{Publisher's Note}

Springer Nature remains neutral with regard to jurisdictional claims in published maps and institutional affiliations.

\section{Author details}

'Faculty of Epidemiology \& Population Health, London School of Hygiene \& Tropical Medicine, Keppel Street, London WC1E 7HT, UK. ${ }^{2}$ Guttmacher Institute, 125 Maiden Lane 7th Floor, New York, NY 10038, USA.

\section{Received: 10 April 2018 Accepted: 30 August 2018}

\section{Published online: 10 September 2018}

\section{References}

1. United Nations. Transforming our world: the 2030 agenda for sustainable development. In: Resolution adopted by the general assembly on 25 September 2015; 2015. p. 1-35.

2. Kruk M, Kujawski S, Moyer CA, Adanu RM, Afsana K, Cohen J, et al. Next generation maternal health: external shocks and health system innovations. Lancet. 2016:6736:1-11.

3. Dzakpasu S, Powell-Jackson T, Campbell OMR. Impact of user fees on maternal health service utilization and related health outcomes: a systematic review. Health Policy Plan. 2014;29:137-50.

4. Meessen B, Hercot D, Noirhomme M, Ridde V, Tibouti A, Tashobya CK, et al. Removing user fees in the health sector: a review of policy processes in six sub-Saharan African countries. Health Policy Plan. 2011;26(SUPPL. 2):16-29.

5. Dawson AJ, Buchan J, Duffield C, Homer CSE, Wijewardena K. Task shifting and sharing in maternal and reproductive health in low-income countries: a narrative synthesis of current evidence. Health Policy Plan. 2014;29:396-408.

6. Van Lonkhuijzen L, Stekelenburg J, Van Roosmalen J. Maternity waiting facilities for improving maternal and neonatal outcome in low-resource countries. Cochrane Database Syst Rev. 2009;3:CD006759.

7. Phillips JF, Greene WL, Jackson EF. Lessons from community-based distribution of family planning in Africa of family planning in Africa. 1999.

8. Campbell OMR, Calvert C, Testa A, Strehlow M, Benova L, Keyes E, et al. The scale, scope, coverage, and capability of childbirth care. Lancet. 2016;388: 2193-208.

9. Hanson K, Gilson L, Goodman C, Mills A, Smith R, Feachem R, et al. Is private health care the answer to the health problems of the World's poor? PLoS Med. 2008:5:1529-32.

10. The World Bank. Financing health services in developing countries: an agenda for reform. 1987.

11. Nishtar S. Public - private "partnerships" in health - a global call to action. Heal res policy Syst. 2004:2:5.

12. Bennett $S, M c P a k e ~ B$, Mills $A$. The public/private mix debate in health care In: Bennett S, McPake B, Mills A, editors. Private Health Providers in Developing Countries. London; New Jersey: Zed Books Ltd; 1997. p. 1-18.

13. Horton $\mathrm{R}$, Clark $\mathrm{S}$. The perils and possibilities of the private health sector. Lancet. 2016:6736:2-3.

14. Basu S, Andrews J, Kishore S, Panjabi R, Stuckler D. Comparative performance of private and public healthcare Systems in low- and Middle-Income Countries: a systematic review. PLoS Med. 2012;9: e1001244. https://doi.org/10.1371/journal.pmed.1001244.

15. Olivier J, Wodon Q. Market share of faith-inspired health care providers in Africa: comparing facilities and multi-purpose integrated household survey data. In: Olivier J, Wodon Q, editors. The role of faith-inspired health care providers in sub-Saharan Africa and public-private partnerships: strengthening the evidence for faith-inspired health engagement in Africa, vol. 1. Washington, DC: The International Bank for Reconstruction and Development/The World Bank; 2012.

16. Anderson S. Public, private, neither, both? Publicness theory and the analysis of healthcare organisations. Soc Sci Med. 2012;74:313-22.

17. Perry JL, Rainey HG. The public-private distinction in organization theory: a critique and research strategy. Acad Manag Rev. 1988;13:182-201.

18. Peters DH, Mirchandani GG, Hansen PM. Strategies for engaging the private sector in sexual and reproductive health: how effective are they? Health Policy Plan. 2004;19(Suppl 1):15-21.

19. Berman $P$, Rose $L$. The role of private providers in maternal and child health and family planning services in developing countries. Health Policy Plan. 1996;11:142-55

20. Campbell OMR, Benova L, Macleod D, Goodman C, Footman K, Pereira AL, et al. Who, what, where: an analysis of private sector family planning provision in 57 low- and middle-income countries. Trop Med Int Heal. 2015;00:1-18.

21. Ugaz Jl, Chatterji M, Gribble JN, Mitchell S. Regional trends in the use of short-acting and long-acting contraception accessed through the private and public sectors. Int J Gynecol Obstet. 2015;130(Suppl. 3):E3-7.

22. Agha S, Do M. Does an expansion in private sector contraceptive supply increase inequality in modern contraceptive use? Health Policy Plan. 2008; 23:465-75.

23. Obare F, Warren C, Abuya T, Askew I, Bellows B. Assessing the populationlevel impact of vouchers on access to health facility delivery for women in Kenya. Soc Sci Med. 2014;102:183-9.

24. Obare F, Warren C, Kanya L, Abuya T, Bellows B. Community-level effect of the reproductive health vouchers program on out-of-pocket spending on family planning and safe motherhood services in Kenya. BMC Health Serv Res. 2015:15:343.

25. Wang, WJ, Wang SX, Pullum T, Ametepi P. How family planning supply and the service environment affect contraceptive use: findings from four East African countries. DHS Analytical Studies No. 26. Calverton. Maryland: ICF International; 2012.

26. Chapman S, Jafa K, Longfield K, Vielot N, Buszin J, Ngamkitpaiboon L, et al. Condom social marketing in sub-Saharan Africa and the Total market approach. Sex Health. 2012;9:44-50.

27. Delamou A, Koivogui A, Dubourg D, Delvaux T. Family planning in Guinea: a need for better public commitment. Trop Med Int Heal. 2014;19:65-73.

28. Fotso JC, Speizer IS, Mukiira C, Kizito P, Lumumba V. Closing the poor-rich gap in contraceptive use in urban Kenya: are family planning programs increasingly reaching the urban poor? Int J Equity Health. 2013;12:71.

29. Hotchkiss DR, Godha D, Do M. Effect of an expansion in private sector provision of contraceptive supplies on horizontal inequity in modern contraceptive use: evidence from Africa and Asia. Int J Equity Health. 2011:10:33.

30. Johnson FA, Padmadas SS, Brown JJ. On the spatial inequalities of institutional versus home births in Ghana: a multilevel analysis. J Community Health. 2009;34:64-72.

31. Khan S, Mishra V, Arnold F, Abderrahim N. Contraceptive trends in developing countries. DHS comparative reports No. 16. Calverton: Macro International Inc; 2007.

32. Limwattananon S, Tangcharoensathien $\mathrm{V}$, Sirilak S. Trends and inequities in where women delivered their babies in 25 low-income countries: evidence from demographic and health surveys. Reprod Health Matters. 2011;19:75-85.

33. Nguyen $\mathrm{H}$, Snider J, Ravishankar N, Magvanjav O. Assessing public and private sector contributions in reproductive health financing and utilization for six sub-Saharan African countries. Reprod Health Matters. 2011;19:62-74.

34. Bazant ES, Koenig MA, Fotso J-C, Mills S. Women's use of private and government health facilities for childbirth in Nairobi's informal settlements. Stud Fam Plan. 2009:40:39-50.

35. Waiswa P, Akuze J, Peterson S, Kerber K, Tetui M, Forsberg BC, et al. Differences in essential newborn care at birth between private and public health facilities in eastern Uganda. Glob Health Action. 2015;8:24251.

36. Ganle JK, Parker M, Fitzpatrick R, Otupiri E. Inequities in accessibility to and utilisation of maternal health services in Ghana after user-fee exemption: a descriptive study. Int J Equity Health. 2014;13:89.

37. O'Meara WP, Karuru S, Fazen LE, Koech J, Kizito B, Tarus C, et al. Heterogeneity in health seeking behaviour for treatment, prevention and urgent care in four districts in western Kenya. Public Health. 2014;128:993-1008.

38. Onwujekwe OE, Enemuoh JC, Ogbonna C, Mbachu C, Uzochukwu BS, Lawson A, et al. Are modern contraceptives acceptable to people and 
where do they source them from across Nigeria? BMC Int Health Hum Rights. 2013;13:7.

39. Oye-Adeniran BA, Adewole IF, Umoh AV, Oladokun A, Gbadegesin A, Odeyemi KA, et al. Sources of contraceptive commodities for users in Nigeria. PLoS Med. 2005;2:e306.

40. Oye-Adeniran BA, Adewole IF, Umoh AV, Oladokun A, Ghadegsin A, Ekanem EE, et al. Community-based study of contraceptive behaviour in Nigeria. Afr J Reprod Health. 2006;10:90-104.

41. Sidze EM, Lardoux S, Speizer IS, Faye CM, Mutua MM, Badji F. Young women's access to and use of contraceptives: the role of providers' restrictions in urban Senegal. Int Perspect Sex Reprod Health. 2014;40:176-83.

42. White JN, Corker J. Applying a Total Market Lens: Increased IUD Service Delivery Through Complementary Public- and Private-Sector Interventions in 4 Countries. Glob Health Sci Pract. 2016;4:21-32.

43. Adogu POU, Egenti BN, Ubajaka C, Onwasigwe C, Nnebue CC. Utilization of maternal health services in urban and rural communities of Anambra state, Nigeria. Niger J Med. 2014;23:61-9.

44. Amin R. Contraceptive use and desire for more children in two rural districts of Sierra Leone. J Biosoc Sci. 1998;30:287-96.

45. Chakraborty N, Mbondo M, Simmons R, Wanderi J. Evaluating the impact of social franchising on family planning use, and provider volume and revenue, in Kenya SIFPO end of project symposium. J heal Popul Nutr. 2016:1-9.

46. Hodgkin D, Received I, August I. Household characteristics affecting where mothers deliver in rural Kenya. Health Econ. 1996;5:333-40.

47. Ikeako LC, Onah HE, lloabachie GC. Influence of formal maternal education on the use of maternity services in Enugu, Nigeria. J Obstet Gynaecol (Lahore). 2006;26:30-4.

48. Iyaniwura CA, Yussuf Q. Utilization of antenatal care and delivery services in Sagamu, South Western Nigeria. Afr J Reprod Health. 2009;13:111-22.

49. Kruk ME, Mbaruku G, McCord CW, Moran M, Rockers PC, Galea S. Bypassing primary care facilities for childbirth: a population-based study in rural Tanzania. Health Policy Plan. 2009;24:279-88.

50. MLE, Tupange, KNBS. Report of the baseline household survey for the Kenya urban reproductive health initiative (Tupange). 2011.

51. Egede JO, Onoh RC, Umeora J, lyoke CA, Benedict I, Dimejesi O, et al. Contraceptive prevalence and preference in a cohort of south-east Nigerian women. Patient Prefer Adherence. 2015;9:707-14.

52. Olusanya BO, Roberts AA, Olufunlayo TF, Inem VA. Preference for private hospital-based maternity services in inner-city Lagos, Nigeria: an observational study. Health Policy (New York). 2010;96:210-6.

53. Lafort Y, Lessitala F, Candrinho B, Greener L, Greener R, Beksinska M, et al. Barriers to HIV and sexual and reproductive health care for female sex workers in Tete, Mozambique: results from a cross-sectional survey and focus group discussions. BMC Public Health. 2016;16:608.

54. Echoka E, Kombe Y, Dubourg D, Makokha A, Evjen-Olsen B, Mwangi M, et al. Existence and functionality of emergency obstetric care services at district level in Kenya: theoretical coverage versus reality. BMC Health Serv Res. 2013;13:113.

55. Matshidze KP, Richter LM, Ellison GT, Levin JB, Mclntyre JA. Caesarean section rates in South Africa: evidence of bias among different "population groups". Ethn Health. 1998:3:71-9.

56. Tabatabai P, Henke S, Susac K, Kisanga OME, Baumgarten I, Kynast-Wolf G, et al. Public and private maternal health service capacity and patient flows in southern Tanzania: using a geographic information system to link hospital and national census data. Glob Health Action. 2014;7:22883.

57. Campbell OMR, Benova L, Macleod D, Baggaley RF, Rodrigues LC, Hanson K, et al. Family planning, antenatal and delivery care: crosssectional survey evidence on levels of coverage and inequalities by public and private sector in 57 low- and middle-income countries. Trop Med Int Heal. 2016;21:486-503.

58. Hopstock P, Sherpick A, Briceno C, Investments PF. Providers and Consumers of Commercial Family Planning Service in Developing Countries; 1997. p. 22209.

59. Winfrey W, Heaton L, Fox T, Adamchack S. Factors influencing the growth of the commercial sector in family planning service provision. 2000.

60. Benova L, Macleod D, Footman K, Cavallaro F, Lynch CA, Campbel OMR. The role of the private sector in delivery in low-income and middle-income countries: a retrospective, observational analysis of demographic and health surveys from 57 countries. New Voices Global Health. 2014:384(Suppl. 1):S4.
61. Benova L, Macleod D, Footman K, Cavallaro F, Lynch CA, Campbell OMR. Role of the private sector in childbirth care: cross-sectional survey evidence from 57 low- and middle-income countries using demographic and health surveys. Trop Med Int Heal. 2015;20(12):1657-73.

62. Bradley SEK, Croft TN, Fishel JD. Revising Unmet Need for Family Planning: DHS Analytical Studies No. 25; 2012. p. 63.

63. Ayad M, Wilkinson M, McNiff M. Sources of contraceptive methods. Calverton; 1994

64. Aremu O. The influence of socioeconomic status on women's preferences for modern contraceptive providers in Nigeria: a multilevel choice modeling. Patient Prefer Adherence. 2013;7:1213-20.

65. Lewis MA, Kenney G. The private sector and family planning in developing countries: its role, achievements and potential. 1988.

66. Rosen JE, Conly SR. Getting down to business: expanding the private commercial sector's role in meeting reproductive health needs. Washington: Population Action International; 1999.

67. Ross J, Stover J, Adelaja D. Profiles for family planning and reproductive health programs: 116 countries. 2nd ed. Glastonbury: Futures Group; 2005.

68. Wodon Q, Nguyen MC, Tsimpo C. Market share of faith-inspired and private secular health care providers in Africa: comparing DHS and multi-purpose integrated surveys. In: Olivier J, Wodon Q, editors. The role of faith-inspired health care providers in sub-Saharan Africa and public-private partnerships: strengthening the evidence for faith-inspired health engagement in Africa, volume 1. Washington, DC: The International Bank for Reconstruction and Development/The World Bank; 2012. p. 27-40.

69. Bell J, L.curtis S, Alayon S. Trends in Delivery Care in Six Countries. DHS Analytical studies No.7. ORC Macro Calverton: Maryl USA Int; 2003. p. 1-62.

70. Yoong J, Burger N, Spreng C, Sood N. Private sector participation and health system performance in sub-Saharan Africa. PLoS One. 2010;5:e13243.

71. Brugha R, Pritze-Aliassime S. Promoting safe motherhood through the private sector in low- and middle-income countries. Bull World Health Organ. 2003:81:616-23.

72. Nketiah-Amponsah E, Arthur E. Choice of delivery facility among expectant mothers in Ghana: does access to health insurance matter? J Health Manag. 2013;15:509-24.

73. Osubor KM, Fatusi AO, Chiwuzie JC. Maternal health-seeking behavior and associated factors in a rural Nigerian community. Matern Child Health J. 2006;10:159-69.

74. Ross DA, Dick B, Ferguson J. Preventing HIV/AIDS in Young People: A systematic review of the evidence from developing countries. WHO Tech Rep Ser. 2006:938:1-13.

75. World Health Organization. Making pregnancy safer: the critical role of the skilled attendant. A joint statement by WHO, ICM and FIGO. Geneva: Switz WHO; 2004. p. 1-18.

76. Footman K, Benova L, Goodman C, Macleod D, Lynch CA, Penn-Kekana L, et al. Using multi-country household surveys to understand who provides reproductive and maternal health services in low- and middle-income countries: a critical appraisal of the demographic and health surveys. Trop Med Int Heal. 2015:20:589-606.

77. Duff JF, Buckingham WW. Strengthening of partnerships between the public sector and faith-based groups. Lancet. 2015;386:1786-94.

78. Tomkins A, Duff J, Fitzgibbon A, Karam A, Mills EJ, Munnings K, et al. Controversies in faith and health care. Lancet. 2015;386:1776-85.

79. Moyer CA, Mustafa A. Drivers and deterrents of facility delivery in subSaharan Africa: a systematic review. Reprod Health. 2013;10:40.

80. Gabrysch S, Campbell OMR. Still too far to walk: literature review of the determinants of delivery service use. BMC Pregnancy Childbirth. 2009:9:34. 